\title{
sciendo
}

\author{
BULGARIAN ACADEMY OF SCIENCES
}

CYBERNETICS AND INFORMATION TECHNOLOGIES • Volume 21, No 4

Sofia $2021 \quad$ Print ISSN: 1311-9702; Online ISSN: 1314-4081

DOI: $10.2478 /$ cait-2021-0041

\section{Decision Making in Real Estate: Portfolio Approach}

\author{
Todor Stoilov ${ }^{1}$, Krasimira Stoilova ${ }^{1}$, Miroslav Vladimirov $^{2}$ \\ ${ }^{1}$ Institute of Information and Communication Technologies, Bulgarian Academy of Sciences, Acad. G. \\ Bonchev Str. bl.2, 1113 Sofia, Bulgaria \\ ${ }^{2}$ Varna University of Economics, 77 Kniaz Boris Bul., 9002 Varna, Bulgaria \\ E-mails: todor.stoilov@iict.bas.bg krasimira.stoilova@iict.bas.bgvvladimirov@ue-varna.bg
}

\begin{abstract}
An investment policy is suggested about assets on real estate markets. Such analysis recommends investments in non-financial assets and optimization of the results from such decisions. The formalization of the investment policy is based on the portfolio theory for asset allocation. Two main criteria are applied for the decision making: return and risk. The decision support is based on Mean-Variance portfolio model. A dynamical and adaptive investment policy is derived for active portfolio management. Sliding procedure in time with definition and solution of a set of portfolio problems is applied. The decision defines the relative value of the investment to which real estates are to be allocated. The regional real estate markets of six Bulgarian towns, which identify the regions with potential for investments, are compared. The added value of the paper results in development of algorithm for a quantitative analysis of real estate markets, based on portfolio theory.
\end{abstract}

Keywords: Decision-making, portfolio theory, portfolio optimization, real estates.

\section{Introduction}

The decision making process has internal complexity due to the requirements for considering a set of criteria, which complicates the process of finding appropriate solution, satisfying different even contradictory optimization criteria. For the case of single optimization criterion, the decision problem can be formalized easily as optimization problem. In the multicriteria case the decision is difficult and various quantitative and fuzzy approaches can be found for resolving such a task. This paper does not claim in making profound analysis for decision making formalizations. For illustration purposes the reader can follow the researches and the appropriate references from [1-10].

This research applies another methodological background, which is based on the formal definition of the portfolio theory [11-13]. The goal of this research is to develop an algorithm for decision making of investments in the domain of real estate trade. For satisfying this goal several problems are to be discussed: assessment of the real estate market in Bulgaria; the portfolio theory and its optimization problems; 
decision making with data of real estate market in Bulgaria; comparisons of the real estate markets of several cities.

The formal models of the portfolio theory are applied in this research to estimate in a quantitative way the decisions about trades of real estates. The portfolio application here addresses real estate market in Bulgaria and makes estimations about the potential for investments in National and regional scales.

An internal complication of each investment process is the case that at the time of the decision making it has to be forecast the future behavior of the market, because for this future moment the benefit of the investment cannot be evident. For the time of decision it is easy to consider all sets of conditions, goals and factors which motivate the request for the investment. But the investment results will be available in the future and for this time the quantitative parameters and conditions are unknown. Such complication is natural for each investment process [14]. This is a methodological difficulty which solutions are based on forecasting the future behavior and market state. Such complicated conditions, well-known history and current state and unknown future behavior are explicitly assumed in the portfolio theory. Latter considers the stochastic unknown future behavior of the market and introduces the portfolio parameter risk as a quantitative assessment of the future unknown characteristics of the portfolio. Additionally, the portfolio theory applies simultaneously two important criteria for the decision making: risk and return for the investment. These considerations motivate the usage of the portfolio theory for supporting the investment decisions in real estates, which is targeted in this research.

The paper is organized in seven sections. Section 2 discusses the system of monitoring the market of real estate in Bulgaria. The main indices about the old and new dwelling are introduced. The main source of market information used for the portfolio problems definition is explained. The main formal background about the definition and solution of the portfolio theory is presented in Section 3. The outcomes and peculiarity of the portfolio problem and the simultaneous usage of risk and return of the main goals of the investment policy are discussed. In Section 4 the application of the portfolio problems in a sequence of algorithmic computational algorithm is introduced. This algorithm applies sliding evaluation sequence of definition and solution of a set of portfolio problems. The resulting investment strategy makes adaptation of the portfolio parameters, following the dynamics of the real estate market. In Section 5 the algorithm of sliding evaluations is applied for the regional real estate markets for six biggest towns in Bulgaria. The results of the evaluations recommend potential investment in new and/or old dwellings in appropriate combination. Additionally, the investment efficiency for the regional markets is compared. The conclusions make recommendation for improvement and extension of the applied algorithm for assessment of the regional real estate's markets.

\section{Assessment of the real estate market in Bulgaria}

On national level in Bulgaria the State National Statistical Institute currently follows the market on real estates and provides acquiring data about the prices, volumes of trades, and changes of the market. This information results in definition and current 
evaluation of general and regional indices, named House Price Indices (HPI) $[15,16]$. These data are formalized according to harmonized definitions and concepts, included in the Owner-occupied Housing Commission Regulation N93/2013, Regulation (EU) 2016/792. The HPI indices contain two main components:

- HPI of new dwellings, which assesses the category for new built and existing but new to the householder sector. This category of real estates in this research is named "New";

- HPI of existing dwellings, which are currently trading between householders. This category here is "Old".

The HPI values concern market prices of dwellings, mainly apartments because the market for houses is not significant at present. Thus, HPI index covers only purchases of apartments.

The paper uses as input data the values of these two HPI indices for the "New" and "Old" estates. The value of each index is evaluated for 3 months period, which results in 4 numbers per quarter for a year.

Applying the notations $\operatorname{HPI}(t)$ and $\operatorname{HPI}(t-1)$ as values of indices for two sequential quarters, $t$ and the previous $t-1$, it is easy to estimate the return of an investment for the time moment $t$ in comparison with the previous one $t-1$.

Analytically, the return from buying estate in time $t-1$ and selling it in time $t$ is evaluated as

$$
\operatorname{Return}(t)=(\operatorname{HPI}(t)-\operatorname{HPI}(t-1)) /(\operatorname{HPI}(t)) \text {. }
$$

The meaning of the value Return $(t)$ gives the profit of a trade if a householder has bought an estate at time $t-1$ and sells it at time $t$. The profit of this trade operation is evaluated in \%. Applying the relation above the HPI indices for "New" and "Old" estates are evaluated as a sequence of profits, each value for the current quarter defines the return based on the previous quarter. The form of presentation of National based HPI indices is illustrated in Fig. 1. Having such format of the initial data, this research applies the portfolio theory to assess the benefits in trading "New" and "Old" estates. Here it is assumed that the HPI of values represent the historical data of returns of two portfolio assets.

Hence, the portfolio model will be applied for the case of $N=2$ assets, "New" and "Old". The decision for the investment is formalized, following the portfolio theory.

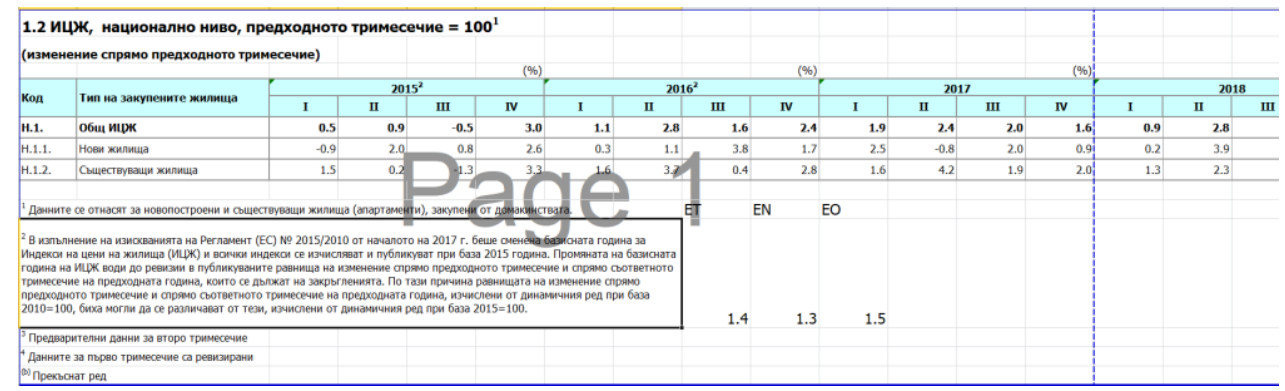

Fig. 1. Initial view of the National HPI data [15] 


\section{Portfolio theory and its optimization problems}

The main outcome of the application of the portfolio theory is that it gives solution how to allocate the investment resources among a set of assets. The solution of the portfolio optimization recommends to the decision makers how many and which assets have to be bought now by means of which in the future they will give return by their selling [12]. The decision goal is to invest today in order to obtain return later. The decision maker must estimate the best combination of assets in the portfolio in order to maximize his/her return. A formal model for supporting such decisionmaking is worked out in the portfolio theory $[12,17,18]$. An optimization problem is defined, which solution gives optimal weights of assets, which have to be retained in the portfolio. The decision-making process targets maximization of the return but simultaneously by minimizing the investment risk [13, 19, 20]. The portfolio optimization model is analytically defined in classical form as [21-23]

$$
\underset{\mathbf{w}}{\max }\left[\begin{array}{c}
\mathbf{E}^{\mathrm{T}} \mathbf{w} \\
\mathbf{w}^{\mathrm{T}} \boldsymbol{\Sigma} \mathbf{w} \leq \sigma_{\text {max }}^{2}
\end{array}\right] \text { or } \underset{\mathbf{w}}{\min }\left[\begin{array}{c}
\mathbf{w}^{\mathrm{T}} \mathbf{\Sigma} \mathbf{w} \\
\mathbf{E}^{\mathrm{T}} \mathbf{w} \geq E_{\text {min }}
\end{array}\right],
$$

where: $\mathbf{E}^{\mathrm{T}}=\left(E_{1}, \ldots, E_{N}\right)$ are the mean assets returns;

$N$ - number of type of assets in the portfolio;

$\boldsymbol{\Sigma}$ - the covariance matrix between the asset returns. The components of this matrix give quantitative evaluations of the assets risk and the correlations between the returns of the assets;

$\mathbf{w}^{\mathrm{T}}=\left(w_{1}, \ldots, w_{N}\right), w_{i}$ is the weight of the investment $i$. Generally, it is measured as percentages and/or relative part of the investment. It gives the amount of the investment allocated for buying asset $i$ as a solution of the portfolio problem;

$\sigma_{\max }^{2}$ is the maximal allowed risk for the portfolio;

$E_{\min }$ is the minimal requested return by the portfolio.

These main parameters of the portfolio problem $\mathbf{E}^{\mathrm{T}}$ and $\boldsymbol{\Sigma}$ must be estimated in advance for the portfolio optimization. Mainly their estimation is performed by evaluations with the historical trend of the values of the asset returns [24, 25]. Because the returns are stochastic in nature, they strongly influence the input data for the optimization and different factor models are used for its estimation [26, 27]. This classical Mean-Variance (MV) problem suffers from the sensitivity of the portfolio solutions due to the accuracy of the input data $\mathbf{E}^{\mathrm{T}}, \boldsymbol{\Sigma}$. The stochastic nature of the input data results in unintuitive problem solutions. As a result, many investors consider the MV problem too impractical to be used for real investments. The portfolio problem can be complicated with additional constraints to the optimization problem concerning transactional costs [11,28], subjective forecasts of the asset returns [29-31], predefined structure of the portfolio [32, 23], portfolio problem with probabilistic definition of the risk (Value at Risk) [33, 34]. The formalization of the portfolio problem can be provided in classical mini-max optimization problem [12], by fuzzy models [4, 6, 7], as multicriteria group decision-making problem [2, 4, 35], by bi-level definition of the portfolio problem $[34,36]$. In this research we are following the classical optimization form of portfolio theory by simultaneously maximization of the portfolio return and minimization the risk given in a common goal function. The application of the portfolio theory is connected with different and 
many computations. Thus, without the usage of computational resources one rarely can obtain useful and meaningful results. An overview about the needed evaluations in the formal background of the portfolio theory is presented in [37]. The quantified and formal approach for the analysis and decision making in financial domain is summarized in [12]. The needs for the usage of computational technology in investment decisions are motivated in [35, 37].

In this research the portfolio problem is based on the mean-variance approach, which applies simpler formal relations for the optimization. The multicriteria requirement for maximization of the portfolio return $E_{\mathrm{p}}=\mathbf{E}^{\mathrm{T}} \mathbf{w}$ and minimization of the portfolio risk $\sigma_{\mathrm{p}}^{2}=\mathbf{w}^{\mathrm{T}} \boldsymbol{\Sigma} \mathbf{w}$ is satisfied in a modified portfolio problem, which integrates these requirements

$$
\begin{gathered}
\max _{\mathbf{w}}\left[(1-\lambda) \mathbf{E}^{\mathrm{T}} \mathbf{w}-\lambda \mathbf{w}^{\mathrm{T}} \boldsymbol{\Sigma} \mathbf{w}\right], \\
\mathbf{w}^{\mathrm{T}}|\mathbf{1}|=1, \mathbf{w}^{\mathrm{T}} \geq 0 .
\end{gathered}
$$

The parameter $\lambda \in[0,1]$ is the risk aversion coefficient. It has to be chosen by the investor by means to quantify the importance from these two criteria: risk and return. For $\lambda=0$, the investor is bold and he does not consider the existence of risk. The portfolio problem (2) maximizes only the return. For $\lambda=1$ the investor is scare from the risk, he does not care about the portfolio return. In this case the portfolio problem makes minimization of the risk, which is the only goal targeted by the investor.

For the set of values $\lambda \in[0,1]$ the portfolio problem (2) has different solutions $\mathbf{w}$, which result in different portfolio risks and returns. The graphical presentation of these portfolio values gives a convex curve in the space Return(w)[Risk(w)], named "Efficient frontier" [21, 23] (Fig. 2).

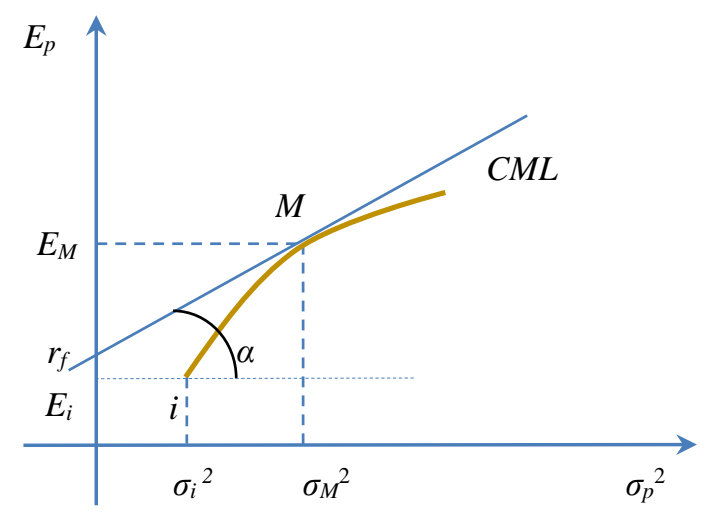

Fig. 2. Graphical presentation of the "Efficient frontier"

From this set of portfolio solutions the decision maker has to choose one point, which will be one's final choice of the optimal investment $\mathbf{w}^{\text {opt }}$. The components of this vector $\mathbf{w}^{\mathrm{opt}}$ give different amount of assets in the portfolio. A practical recommendation for the decision maker is to evaluate all sets of portfolios, which belong to the Efficient frontier. Then from this curve, the decision maker has to choose one point for his portfolio, which corresponds to the investor's preference for relation between the portfolio risk and portfolio return. Due to considerations for 
maximizing the return and minimizing the risk it is widely applied the relation between these two criteria named "Excess Sharpe Ratio" [20]

$$
\text { Ex }_{\text {Sharpe }_{\text {Ratio }}}=\operatorname{tg}(\alpha) \equiv \mathbf{w}^{\text {opt }}=\left\{\max _{\mathbf{w}} \frac{\mathbf{E}^{\mathrm{T}} \mathbf{w}-r_{\mathrm{f}}}{\mathbf{w}^{\mathrm{T}} \boldsymbol{\Sigma} \mathbf{w}}\right\},
$$

where $r_{\mathrm{f}}$ is the return of risk free asset, which has 0 risk (deposit).

This research applies this approach for choosing a unique portfolio solution, having evaluated a set of portfolios, belonging to the Efficient frontier.

\section{Computational algorithm for decision making}

In Fig. 3 the data of the HPI indices at National level are presented in graphical form. These data concern the time period from the year 2015 till 2020. According to Fig.1 these initial data represent a set of values, which give the historical trend of returns of "New" and "Old" assets on National level. In Fig. 3 the historical trend is presented as a graphics in time. The interpretation of this figure says that if the values of "New" are over the "Old" it is recommended to invest in "New" estates. The opposite case gives preferences for investing in "Old" estates.

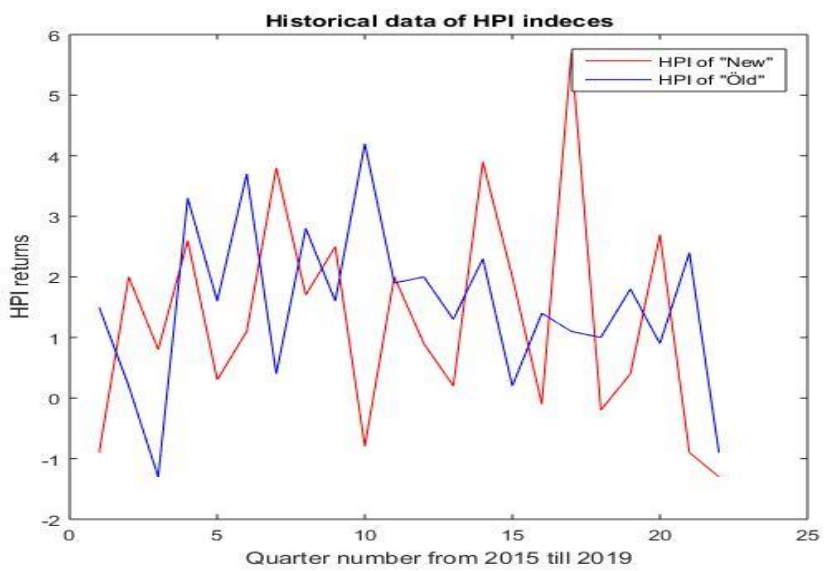

Fig. 3. Historical data of HPI indices for "New" and "Old" real estates

Unfortunately, Fig. 3 does not give clear recommendation about the choice between "New" and "Old" assets because both graphics very frequently interchange their positions. To recommend a practical solution for investment in real estates, it is needed to assess both the potential returns and risks for investments in these forms of assets and to choose the appropriate relation between "New" and "Old" assets. In this paper we apply the methodology of the portfolio theory to evaluate these quantitative parameters of prospective investments. A peculiarity of this research is the application of dynamical investment policy, which can be applied in time and to result in successful investments by means of maximizing the returns and keeping minimization of risk. 
The dynamical investment policy is applied by:

- sliding mode of definition and solution of appropriate portfolio problems;

- application of portfolio theory for identifying the prevailing weight;

- assessing the portfolio solutions and estimating the prevailing weights between both assets for a recommendation in a decision making process.

\subsection{Sliding mode of definition and solution of the portfolio problems}

The data about the HDI indices correspond with the returns of "New" and "Old" assets. For this research, data for the period from 2015 until second quarter of 2020 have been analysed and used. The numerical values of both indices for "New" and "Old" and old assets are given in Table 1. They are taken from the available data from $[15,16]$. These data are used for the definition of a set of portfolio problems. The problem parameters of mean returns $\mathbf{E}$ and covariation matrix $\boldsymbol{\Sigma}$ are evaluated from a set of historical data, given from the time series of the HPI indices. An important parameter is the duration of the historical period.

Table 1. Values of the historical data of returns for "New" and "Old" estates [16]

\begin{tabular}{|c|c|c|c|c|c|c|c|c|c|c|c|}
\hline Year & \multicolumn{4}{|c|}{2015} & \multicolumn{4}{|c|}{2016} & \multicolumn{3}{|c|}{2017} \\
\hline Quarter & 1 & 2 & 3 & 4 & 5 & 6 & 7 & 8 & 9 & 10 & 11 \\
\hline Returns "New", $R_{\text {New }}$ & -0.9 & 2.0 & 0.8 & 2.6 & 0.3 & 1.1 & 3.8 & 1.7 & 2.5 & -0.8 & 2.0 \\
\hline Returns "Old", Rold & 1.5 & 0.2 & -1.3 & 3.3 & 1.6 & 3.7 & 0.4 & 2.8 & 1.6 & 4.2 & 1.9 \\
\hline Year & 2017 & \multicolumn{4}{|c|}{2018} & \multicolumn{4}{|c|}{2019} & \multicolumn{2}{|c|}{2020} \\
\hline Quarter & 12 & 13 & 14 & 15 & 16 & 17 & 18 & 19 & 20 & 21 & 22 \\
\hline Returns "New", $R_{\text {New }}$ & -0.9 & 0.2 & 3.9 & 2.0 & -0.1 & 5.7 & -0.2 & 0.4 & 2.7 & -0.9 & -1.3 \\
\hline Returns “Old", Rold & 2.0 & 1.3 & 2.3 & 0.2 & 1.4 & 1.1 & 1.0 & 1.8 & 0.9 & 2.4 & -0.9 \\
\hline
\end{tabular}

In this research it has been chosen the historical period for each portfolio problem to be in duration of 3 quarters ( 9 months). This period is chosen as minimal time for preparing documents for trades of real estate in Bulgaria. This choice defines that the portfolio parameters for mean returns of assets $E_{i}, i=1,2$, and the covariance matrix between their returns $\boldsymbol{\Sigma}$ are evaluated with data of three sequential quarters. Thus, the parameters $\mathbf{E}$ and $\boldsymbol{\Sigma}$ define analytically the current portfolio problem (2). It is solved with different values of the parameter $\lambda \in[0,1]$. Thus, the points of the current Efficient frontier are evaluated numerically. The portfolio, which is chosen by the decision maker, has maximal "Excess Sharpe Ratio", according to (3).

In that manner, the values of the optimal weights $\mathbf{w}^{\mathrm{opt}}=\left[w_{\mathrm{New}}^{\mathrm{opt}}, w_{\mathrm{Old}}^{\mathrm{opt}}\right]^{\mathrm{T}}$ are found. The comparison between the components $w_{\mathrm{New}}^{\mathrm{opt}}$ and $w_{\mathrm{Old}}^{\mathrm{opt}}$ defines a preference of choice of the decision maker as:

- if $\left(w_{\mathrm{New}}^{\mathrm{opt}}>w_{\mathrm{Old}}^{\mathrm{opt}}\right) \Rightarrow$ recommendation for investment in "New" real estates;

- if $\left(w_{\mathrm{New}}^{\mathrm{opt}}<w_{\mathrm{Old}}^{\mathrm{opt}}\right) \Rightarrow$ the recommendation is for "Old" real estates.

After conclusion of these evaluations, the historical time period is moving one quarter ahead (Fig. 4). 

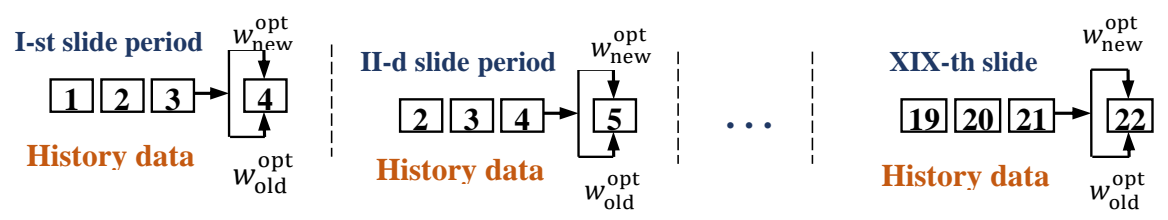

Fig. 4. Sliding mode of portfolio evaluations

Because the input data contain 22 values per quarter about the available HPI data, this requires calculations of 19 Efficient frontiers. Respectively, 19 sets of solutions $\mathbf{w}^{\mathrm{opt}}=\left[w_{\mathrm{New}}^{\mathrm{opt}}, w_{\mathrm{Old}}^{\mathrm{opt}}\right]^{\mathrm{T}}$ will be evaluated, applying the choice for maximal Excess Sharpe Ratio, from the points of the Efficient frontiers. The prevailing values of $w_{\mathrm{New}}^{\mathrm{opt}}$ or $w_{\mathrm{Old}}^{\mathrm{opt}}$ define the recommendation to the decision maker for the choice of investment in "New" or "Old" real estate.

\subsection{Computational algorithm in six steps of evaluations}

The sequence of calculations is presented as computer computational algorithm.

1) Evaluations for a sliding period $k=1$ and $t=\left[t_{1}, t_{2}, t_{3}\right]=[3 k-2,3 k-1,3 k]$

where $t$ is the set of three sequential quarters

2) Evaluation of mean returns for "New" and "Old" assets

where

$$
\begin{gathered}
\mathbf{E}^{(k)}=\left[E_{\mathrm{New}}^{(k)}, E_{\mathrm{Old}}^{(k)}\right]^{\mathrm{T}}, \\
E_{\mathrm{New}}^{(k)}=\frac{1}{3}\left[R_{\mathrm{New}}^{(k)}\left(t_{1}\right)+R_{\mathrm{New}}^{(k)}\left(t_{2}\right)+R_{\mathrm{New}}^{(k)}\left(t_{3}\right)\right], \\
E_{\text {Old }}^{(k)}=\frac{1}{3}\left[R_{\text {Old }}^{(k)}\left(t_{1}\right)+R_{\text {Old }}^{(k)}\left(t_{2}\right)+R_{\text {Old }}^{(k)}\left(t_{3}\right)\right] .
\end{gathered}
$$

3) Evaluation of the covariance matrix

$$
\begin{aligned}
& \boldsymbol{\Sigma}^{(k)}=\left|\begin{array}{ccc}
\operatorname{cov}_{11}^{(k)} & \ldots & \operatorname{cov}_{12}^{(k)} \\
\operatorname{cov}_{21}^{(k)} & \ldots & \operatorname{cov}_{22}^{(k)}
\end{array}\right|, \text { where } \\
& \operatorname{cov}_{i j}^{(k)}=\frac{1}{3}\left[\left(R_{\text {New }}^{(k)}\left(t_{1}\right)-E_{\text {New }}^{(k)}\right)\left(R_{\text {Old }}^{(k)}\left(t_{1}\right)-E_{\text {Old }}^{(k)}\right)+\right. \\
& +\left(R_{\text {New }}^{(k)}\left(t_{2}\right)-E_{\text {New }}^{(k)}\right)\left(R_{\text {Old }}^{(k)}\left(t_{2}\right)-E_{\text {Old }}^{(k)}\right)+ \\
& \left.+\left(R_{\text {New }}^{(k)}\left(t_{3}\right)-E_{\text {New }}^{(k)}\right)\left(R_{\text {old }}^{(k)}\left(t_{3}\right)-E_{\text {old }}^{(k)}\right)\right], \quad i, j=1,2 \text {. }
\end{aligned}
$$

The covariance matrix $\boldsymbol{\Sigma}^{(k)}$ is symmetric one and $\operatorname{cov}_{12}^{(k)}=\operatorname{cov}_{21}^{(k)}$. $\boldsymbol{\Sigma}^{(k)}$.

4) Definition and solution of the portfolio problem (2) with parameters $\mathbf{E}^{(k)}$ and

By changing $\lambda \in[0,1]$ multiple solutions of (2) are performed. Each solution gives weights $\mathbf{w}^{(k)}(\lambda)=\left[w_{\mathrm{New}}^{(k)}(\lambda), w_{\mathrm{Old}}^{(k)}(\lambda)\right]^{\mathrm{T}}$. With additional evaluations the 
values of the portfolio risk $\mathbf{w}^{(k) \mathrm{T}}(\lambda) \boldsymbol{\Sigma}^{(k)} \mathbf{w}^{(k)}(\lambda)$ and return $\mathbf{E}^{(k) \mathrm{T}} \mathbf{w}^{(k)}(\lambda)$ give one point of the Efficient frontier.

5) Evaluation of numerical points of the Efficient frontier.

For the experiments in this research $\lambda$ has been changed with increment of 0.01 . This makes 101 portfolio solutions for the numerical evaluations of the current portfolio Efficient frontier.

6) Evaluation of the maximal Excess Sharpe Ratio

$$
\max (\operatorname{tg}(\alpha))=\frac{\mathbf{E}_{M}^{(k) \mathrm{T}}-r_{\mathrm{f}}}{\mathbf{w}^{(k) \mathrm{T}} \boldsymbol{\Sigma}^{(k)} \mathbf{w}^{(k)}} .
$$

Finding the corresponding weights $\mathbf{w}_{\mathrm{opt}}^{(k)}(\lambda)$, they are stored for final assessments with the solution of the next sliding period, $k=1, \ldots, 18$ (Fig. 4).

\section{Decision making with data of real estate market in Bulgaria}

The described computations result with computational workload, which is considerable in amount: numerical evaluations of 19 sets of initial portfolio parameters $\mathbf{E}^{(\boldsymbol{k})}$ and $\boldsymbol{\Sigma}^{(k)} ; 101$ solutions of portfolio optimization problem (2) for evaluation of an Efficient frontier and corresponding Excess Sharpe Returns; evaluations of 19 Efficient frontiers. This set of calculations is performed in computer environment. For illustrative purposes here are given numerical results, obtained from the first sliding period, $k=1$, which concerns the first three values of the HPI series of data: $\mathrm{HPI}(\mathrm{New})=\left[\begin{array}{lll}-0.9 & 2 & 0.8\end{array}\right], \mathrm{HPI}(\mathrm{Old})=\left[\begin{array}{lll}1.5 & 0.2 & -1.3\end{array}\right]$. The average returns and covariance are

$$
\mathbf{E}^{(1)}=\left[\begin{array}{ll}
0.6333 & 0.1333
\end{array}\right]^{\mathrm{T}} \quad \boldsymbol{\Sigma}^{(1)}=\left|\begin{array}{cc}
2.1233 \ldots & -1.1217 \\
-1.1217 \ldots & 1.9633
\end{array}\right| .
$$

The Efficient frontier of this portfolio problem for the first sliding period, $k=1$, is given in Fig. 5.

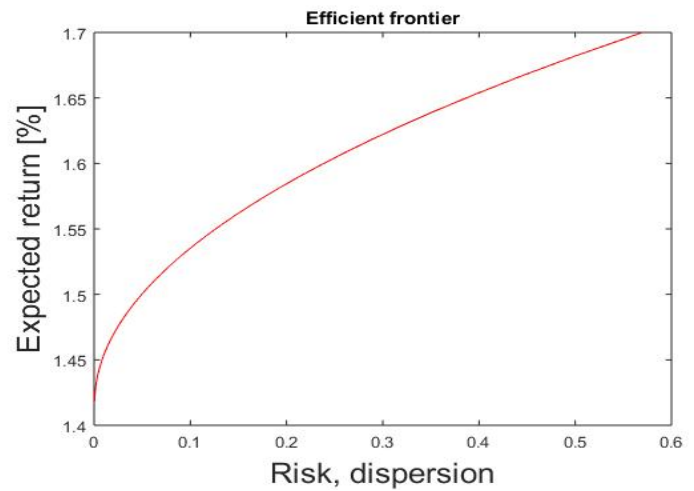

Fig. 5. Efficient frontier for sliding period $k=1$

The maximal Excess Sharpe Ratio is 


$$
\operatorname{tg}(\alpha)=\max \frac{\mathbf{E}^{(k) \mathrm{T}}-r_{\mathrm{f}}}{\mathbf{w}^{(k) \mathrm{T}} \Sigma^{(k)} \mathbf{w}^{(k)}}=0.8277,
$$

where the risk-free return is chosen $r_{\mathrm{f}}=\frac{0.10}{12}$, because the current deposits (risk free asset) return in Bulgarian banks give $0.1 \%$ of early return. The corresponding weights for the maximal Excess Sharpe Return are $\mathbf{w}_{\mathrm{opt}}^{(k)}=\left[\begin{array}{lll}0.5356 & 0.4644\end{array}\right]^{\mathrm{T}}$. For 18 sliding periods the values of $\mathbf{w}_{\mathrm{opt}}^{(k)}, k=1, \ldots, 18$, are given in Table 2 .

Table 2. Values of the portfolio solutions for 18 sliding periods

\begin{tabular}{|l|l|l|l|l|l|l|l|l|l|}
\hline$k$ & 1 & 2 & 3 & 4 & 5 & 6 & 7 & 8 & 9 \\
\hline $\mathrm{w}_{\text {opt }}^{(k)}(\mathrm{New})$ & 0.533 & 1 & 1 & 0.088 & 0.468 & 0.546 & 0.532 & 0.427 & 0.443 \\
\hline $\mathrm{w}_{\mathrm{opt}}^{(k)}(\mathrm{Old})$ & 0.466 & 0 & 0 & 0.911 & 0.531 & 0.453 & 0.467 & 0.572 & 0.556 \\
\hline$k$ & 10 & 11 & 12 & 13 & 14 & 15 & 16 & 17 & 18 \\
\hline $\mathrm{w}_{\mathrm{opt}}^{(k)}(\mathrm{New})$ & 0.476 & 0 & 0 & 0.177 & 0.150 & 0.089 & 0.020 & 0.057 & 0.168 \\
\hline $\mathrm{w}_{\mathrm{opt}}^{(k)}(\mathrm{Old})$ & 0.525 & 1 & 1 & 0.822 & 0.849 & 0.910 & 0.979 & 0.942 & 0.831 \\
\hline
\end{tabular}

The time series of $\mathrm{w}_{\mathrm{opt}}^{(k)}(\mathrm{New})$ and $\mathrm{w}_{\mathrm{opt}}^{(k)}(\mathrm{Old})$ in graphical form are presented in Fig. 6. It is easy to estimate that since the initial 11 quarters the optimal decision is to invest in "Old" real estates. The corresponding curve prevails the curve of "New" real estates and for a long time it keeps values close to the boundary $\mathrm{w}_{\mathrm{opt}}^{(k)}(\mathrm{Old})=1$, which corresponds to $\mathrm{w}_{\mathrm{opt}}^{(k)}(\mathrm{New})=0$ or not recommendations for the "New" real estates.

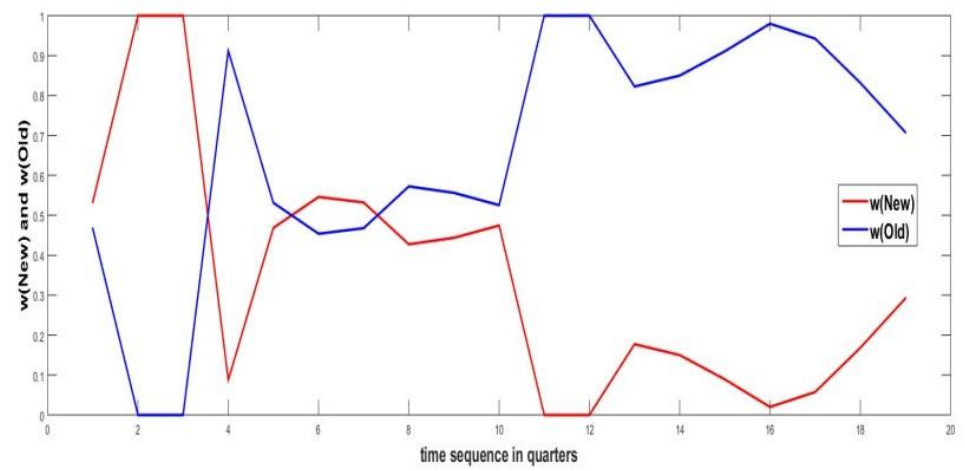

Fig. 6. Graphical presentation of the behaviour of $\mathrm{w}_{\mathrm{opt}}^{(k)}(\mathrm{New})$ and $\mathrm{w}_{\mathrm{opt}}^{(k)}(\mathrm{Old})$ in time

Thus, with the application of portfolio theory in an algorithmic sequence of sliding procedure of evaluations, the pragmatically result for the decision making recommends that investment in "Old" real estate is preferable. Additional confirmation of this result is given by the average values of $\mathrm{w}_{\mathrm{opt}}^{(k)}(\mathrm{New})$ and $\mathrm{w}_{\mathrm{opt}}^{(k)}(\mathrm{Old})$, 


$$
\begin{gathered}
\mathrm{E}_{\mathrm{New}}\left[\mathrm{w}_{\mathrm{opt}}^{(k)}(\mathrm{New})\right]=0.3405, \\
\mathrm{E}_{\text {Old }}\left[\mathrm{w}_{\mathrm{opt}}^{(k)}(\mathrm{Old})\right]=0.6595 .
\end{gathered}
$$

Because $E_{\text {Old }}>E_{N e w}$, the recommendation for the decision maker is again to invest in "Old" real estates.

In Fig. 7 is illustrated the values of portfolio returns, if the investments are made only on "New" or "Old" estates. The figure gives a preference for the "Old" real estate. Its graphics is dominant and stays more time over the graphics of the "New" estates. Thus, according to the criterion "Return", the "Old" estates are preferable for the investment decisions.

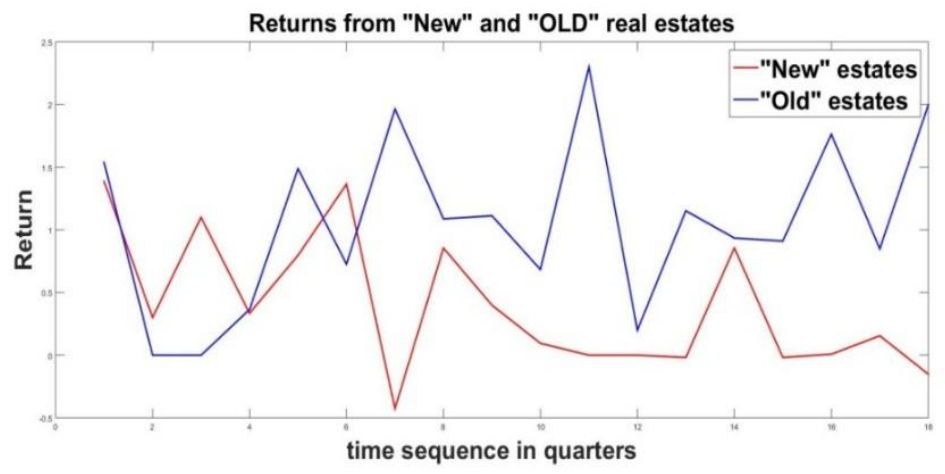

Fig. 7. Returns of investment in "New" and "Old" estates

In Fig. 8 a comparison between the two categories of real estates is done according to the criterion "Risk". This figure shows the risk of portfolios, containing only "New" or "Old" estates. For this case, the portfolio with "Old estates" is dominant. This is not acceptable for the investment procedure due to the higher level of risk for the "Old" real estate.

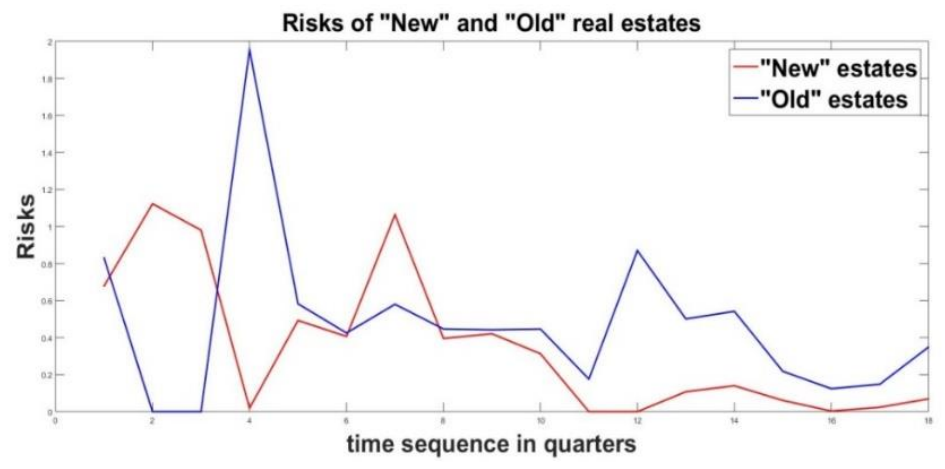

Fig. 8. Risk of investments in "New" and "Old" estates

To find a realistic and useful recommendation for the decision maker here is applied the criterion for maximization of the Sharpe ratio

Sharpe_ratio = Portfolio_Return/Portfolio_Risk. 
The mean values of the Portfolio_Return and Portfolio_Risk are evaluated for the overall sliding procedure of active portfolio management. Thus, the mean values of the Returns and Risks of the graphics from Figs 7 and 8 are given in Table 3. The last column gives results about the values of the Sharpe Ratios. Evidently, the Sharpe ratio of "Old" assets is bigger in comparison with the "New" estates

Sharpe_ratio(Old $)=2.209>1.119=$ Sharpe_ratio $(\mathrm{New})$.

According to this criterion the recommendations for the decision maker is to invest on "Old" real estates.

Table 3. Mean Returns and Risks of Sharpe ratio of "New" and "Old" estates

\begin{tabular}{|c|c|c|c|}
\hline Estates & Mean Return (\%) & Mean Risk (\%) & Sharpe Ratio \\
\hline "New" & 0.3911 & 0.3497 & 1.11833 \\
\hline "Old" & 1.0395 & 0.4796 & 2.2094 \\
\hline
\end{tabular}

These experiments prove that if an investor buys an "Old" real estate and after three quarters in time sells it, the return of the investment will be positive. This cannot be claimed for the case of investment in "New" estates. The model here does not take into consideration the taxes for such business operations, which can be considered additionally for the final assessment and decision.

\section{Comparisons of the real estate markets in the cities}

This part of the researches makes comparisons of the portfolio results, received for the six biggest towns in Bulgaria. The comparison concerns the sliding portfolio optimization procedure, which has been applied for the period of 2015-2020. The initial data are taken for the HPI indices for the six biggest towns: Sofia, Plovdiv, Varna, Burgas, Ruse, Stara Zagora [16]. The assessment of the results is done towards the two main investment criteria: Return and Risk. The combination of these two criteria gives final assessment of the efficiency of the markets in these six towns. The regional assessment of the real estate market allows the potential customers to find a right place for making investments in Bulgaria. That is why local market places for the six biggest towns in Bulgaria are considered. The values of local HPI indices are available in illustrated form, Fig. 9. The HPI indices are evaluated for the period 2015-2020 for each quarter.

The definition and solutions of the appropriate portfolio problems is performed again as a sliding procedure, presented in Section 4 . For the definition of the portfolio problem the HPI data are used as historical records. The portfolio problem has two assets, $N=2$ for "New" and "Old"estates. The history period is again considered for three months. The portfolio solutions are compared with the real market data for the corresponding quarter period. The evaluation procedure is repeated sequentially in a sliding procedure for the period 2015 until 2020. Finally, the evaluations and comparisons in these 17 sliding evaluations define the mean return and mean risk of such active sliding portfolio management of the investment decisions. The content in Table 4 gives the mean values of return and risk for the sliding investment procedure for the regional markets of the six towns. 


\begin{tabular}{|c|c|c|c|c|c|c|c|c|c|c|}
\hline \multicolumn{11}{|c|}{ 2.5 HPI for the six cities in Bulgaria wí } \\
\hline \multicolumn{11}{|c|}{ (quarterly rate of change) } \\
\hline \multirow{2}{*}{ Cities } & \multirow{2}{*}{ Code } & \multirow{2}{*}{ Type of purchase } & \multicolumn{4}{|c|}{2017} & \multicolumn{4}{|c|}{2018} \\
\hline & & & I & II & III & IV & I & II & III & IV \\
\hline \multirow{3}{*}{ Sofia } & H.1. & Total HPI & 1.6 & 3.9 & 2.1 & 1.3 & 0.7 & 4.0 & 0.8 & 1.0 \\
\hline & H.1.1. & New dwellings & 6.8 & 0.2 & -0.3 & -1.9 & -0.5 & 7.3 & 3.1 & -2.4 \\
\hline & H.1.2. & Existing dwellings & -0.8 & 5.8 & 3.1 & 2.8 & 1.3 & 2.6 & -0.2 & 2.6 \\
\hline \multirow{3}{*}{ Plovdiv } & H.1. & Total HPI & 4.4 & 2.3 & 3.1 & 2.4 & 4.0 & 2.9 & 0.1 & 2.3 \\
\hline & H.1.1. & New dwellings & 5.7 & -0.2 & 5.5 & -1.0 & 3.6 & 1.8 & 1.7 & 4.7 \\
\hline & H.1.2. & Existing dwellings & 3.6 & 3.6 & 1.9 & 4.11 & 4.2 & 3.5 & -0.7 & 1.0 \\
\hline \multirow{3}{*}{ Varna $^{4}$} & H.1. & Total HPI & 1.3 & 4.5 & 0.3 & 3.0 & 2.4 & -0.2 & 1.3 & 0.8 \\
\hline & H.1.1. & New dwellings & -3.2 & 4.9 & 1.1 & 4.8 & 1.4 & -2.3 & 3.3 & 0.1 \\
\hline & H.1.2. & Existing dwellings & 3.9 & 4.3 & -0.1 & 2.0 & 2.9 & 1.0 & 0.2 & 1.1 \\
\hline \multirow{3}{*}{ Burgas } & H.1. & Total HPI & 6.0 & -2.2 & 0.7 & 1.4 & -2.6 & 6.9 & 1.6 & 0.4 \\
\hline & H.1.1. & New dwellings & 5.4 & -5.7 & 0.7 & 1.0 & -4.1 & 9.9 & 1.1 & -0.2 \\
\hline & H.1.2. & Existing dwellings & 7.0 & 3.0 & 0.7 & 2.0 & -0.2 & 2.6 & 2.5 & 1.3 \\
\hline \multirow{3}{*}{ Ruse } & H.1. & Total HPI & 5.2 & 3.9 & 2.3 & 3.7 & 2.8 & 1.4 & -1.3 & 1.2 \\
\hline & H.1.1. & New dwellings & 2.4 & -0.6 & 1.9 & 2.9 & 1.3 & 2.6 & -0.4 & 1.5 \\
\hline & H.1.2. & Existing dwellings & 5.7 & 4.7 & 2.4 & 3.8 & 3.0 & 1.2 & -1.4 & 1.1 \\
\hline \multirow{3}{*}{ Stara Zagora } & H.1. & Total HPI & 4.9 & 1.5 & 1.6 & 0.8 & 1.9 & 1.5 & 0.2 & 2.3 \\
\hline & H.1.1. & New dwellings & 9.2 & -0.7 & -1.0 & 2.11 & -1.0 & 0.7 & 2.4 & 1.6 \\
\hline & H.1.2. & Existing dwellings & 3.6 & 2.2 & 2.4 & 0.4 & 2.7 & 1.7 & -0.5 & 2.5 \\
\hline
\end{tabular}

Fig. 9. Illustration about HPI values for six towns [16]

Table 4. Mean values of Risk and Return for applied sliding investment policy on region level

\begin{tabular}{|l|c|c|c|c|}
\hline Town & Mean Risk & Mean Return & Diapason of real return & Recommended estate \\
\hline Sofia & 1.74 & 1.77 & {$[-0.03 ; 3.51]$} & "Old" \\
\hline Plovdiv & 2.47 & 1.69 & {$[0.78 ; 4.16]$} & "Old" \\
\hline Varna & 0.68 & 1.39 & {$[-0.68 ; 2.07]$} & "Old" \\
\hline Burgas & 1.03 & 2.54 & {$[-1.51 ; 3.57]$} & "New" \\
\hline Ruse & 1.11 & 1.25 & {$[-0.14 ; 2.36]$} & "Old" \\
\hline Stara Zagora & 1.58 & 0.9 & {$[0.68 ; 2.48]$} & "Old" \\
\hline
\end{tabular}

The graphical interpretation of these data is given in Fig. 10. The real return of the investment depends on the values of mean Return and means Risk. The lower and upper bounds of the real Return defined its spread (diapason) of changes. The bounds of the real return are evaluated according to the relations:

Lower bound $=$ (mean Return $)-($ mean Risk $)$;

Upper bound $=($ mean Return $)+($ mean Risk $)$.

These values of the spreads are given in column "Diapason of real return" in Table 4. The last column gives the recommendations for investment for "New" or "Old" estates as solution from the portfolio sliding procedure.

The obtained result gives preference for investing in "Old" estates per region. The only exception is the town of Burgas. The only "safe" regions, where the investment procedure can finished always with positive return are Plovdiv and Stara Zagora. Their minimal bounds of the return are positive values. The other regions are not "safe" and can result with negative values of return. It is estimated as the most risky region the town of Burgas.

The portfolio theory requires the assessment of the portfolio investments to be performed simultaneously to both criteria for return and risk. In general, the investors like the return and hate the risk. Thus, following the portfolio problem (2), it is preferable to have maximization in return and minimization of risk. The space, which the portfolio theory makes assessment of set of portfolios with different 
characteristics, is the plane Return/Risk. The horizontal axis concerns the portfolio risk and the vertical one is the portfolio return. The preference on the horizontal axis is a point with most left position. For the vertical axis the preference is to the higher point. Thus, the rule "Nord-West" can give the most preferable portfolio. The results from Table 3 are graphically interpreted in the space Return/Risk in Fig. 11.

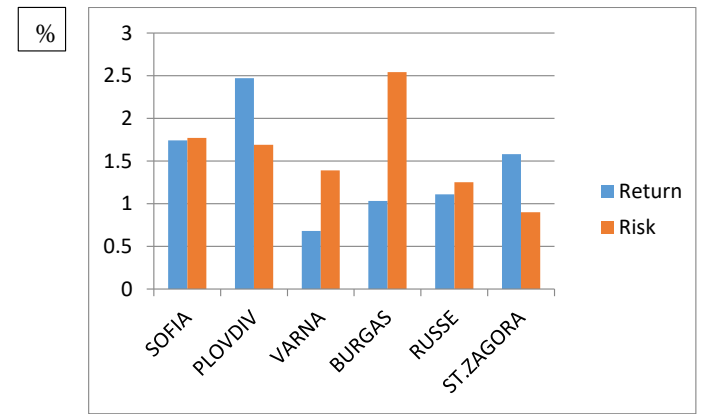

Fig. 10. Graphical presentation of the mean Returns and mean Risks per region

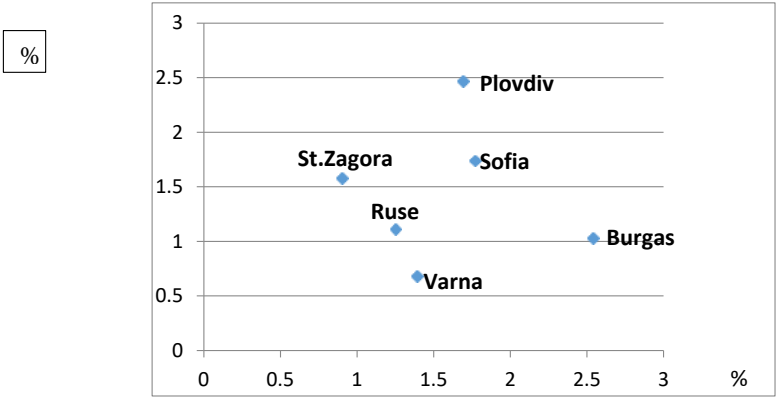

Fig. 11. Comparison of regional portfolio potential for investment in real estates

The most Nord/West situated markets are these of Stara Zagora and Plovdiv. The return from Stara Zagora is lower than Plovdiv but its risk is also lower. Thus, both towns are recommended for investment decisions. The town of Ruse, Sofia and Varna can be regarded as potential place for investments in real estate. They are not leaders in the market. According to the criteria Return and Risk, they can be considered as potential good regions for investment in real estates. The most unfavourable place is the town of Burgas due to its high value of mean Risk. The recommendations for investments in Burgas are for "New" estates. However, the prices of the new estates have high volatility, which results in high risky market.

\section{Conclusion}

The research develops an algorithm for practical solution of an investment problem for decision making between "New" and "Old" real estates. The decision making is based on sequential definition and evaluation of a set of portfolio problems, performed in a sliding mode algorithm. The sequences of evaluations are based on the usage of the short set of initial data of the HPI indices of the real estates for 
historical data, which define the portfolio parameters for mean return and risk. The solutions of the problems such defined are compared with the real HPI data for the next time period. Moving ahead with the HPI data, comparisons are performed between the portfolio solutions and the real data of the market. The applied dynamical sequence of portfolio solutions gives recommendations that the potential investments in "Old" real estates should be preferable by the investors.

The portfolio computations are considerable in amount, because at each sliding step the optimization problem (2) is solved 101 times. Thus, such an economic analysis must be performed always in computer environment because a big set of optimization problems are solved.

This research makes a numerical estimation of the real assets market in Bulgaria on National and on regional levels. The markets of six main towns are taken with the available data of their returns for the period 2015-2020 by quarters. The added value of this research is the application of the portfolio theory for the quantitative estimation of the investment parameters for return, risk and a preference to "New" and/or "Old" real estates. Thus, recommendations for decision making in investing in both types of estates for the regional markets are defined. Special sliding mode portfolio optimization is performed, which assesses the benefit of such investment policy.

Potential future extension of these researches could be the complication of the portfolio problem, considering taxes from this dynamical investment strategy. Another direction of future developments could be in direction for changes of the duration of the historical periods, for the evaluation of the portfolio parameters. This can influence the duration of the investment horizon from one to more quarters. Currently, the authors keep their responsibility only for the current results of the research but they advise the potential users to make also their own market analysis. The applied investment policy proves that if a real estate is bought in the beginning of period of 3 quarters in the end of the period by selling the estate the business operation will result with positive return. The case of increasing the historical period and/or the investment horizon can give potential results for a long time investment and can define the maximal possible return. Such experiments are prospective for a future work of the current research.

Acknowledgments: This work has been supported by project ДН12/10, 20.12.2017 of the Bulgarian National Science fund: Integrated bi-level optimization in information service for portfolio optimization.

\section{References}

1. Kor s e mov, D., D. B or i s s o v a, I. M u s t a k e ro v. Combinatorial Optimization Model for Group Decision-Making. - Cybernetics and Information Technologies, Vol. 18, 2018, No 2, pp. 65-73.

2. B o r i s s o v a, D. Group Decision Making for Selection of k-Best Alternatives. - Compt. Rend. Acad. bulg. Sci., Vol. 69, 2016, No 2, pp. 183-190.

3. B o r i s s o v a, D., I. M u s t a k e r o v, D. K o r s e m o v. Business Intelligence System via Group Decision Making. - Cybernetics and Information Technologies, Vol. 16, 2016, No 3, pp. 219-229. 
4. P e n e v a, V., I. P o p c h e v. Models for Weighted Aggregation of Fuzzy Relations to Multicriteria Decision Making Problems. - Cybernetics and Information Technologies, Vol. 6, 2006, No 3, pp. 3-18.

5. P o p c h e v, I., I. R a d e v a. A Decision Support Method for Investment Preference Evaluation. Cybernetics and Information Technologies, Vol. 6, 2006, No 1, pp. 3-16.

6. P e n e v a, V., I. P o p c h e v. Multicriteria Decision Making Based on Fuzzy Relations. Cybernetics and Information Technologies, Vol. 8, 2008, No 4, pp. 3-12.

7. P e n e v a, V., I. P o p c h e v. Multicriteria Decision Making by Fuzzy Relations and Weighting Functions for the Criteria. - Cybernetics and Information Technologies, Vol. 9, 2009, No 4, pp. 58-71.

8. G e o r g i e v a, P., I. P o p c h e v, S. S t o y a n o v. A Multi-Step Procedure for Asset Allocation in Case of Limited Resources. - Cybernetics and Information Technologies, Vol. 15, 2015, No 3, pp. 41-51.

9. P o p c h e v, I. Soft Computing: Three Decades Fuzzy Models and Applications. - In: Research in Computer Sciences in the Bulgarian Academy of Sciences. K. Atanassov, Ed. Studies in Computational Intelligence. Vol. 934. 2021, pp. 55-100. Switzerland, Springer Nature, 2021. ISSN 1860-949X ISSN 1860-9503 (electronic). ISBN 978-3-030-72283-8 ISBN 978-3-030-72284-5 (eBook). https://doi.org/10.1007/978-3-030-72284-5

10. G e o r g i e v a, P. V. Genetic Fuzzy System for Financial Management. - Cybernetics and Information Technologies, Vol. 18, 2018, No 2, pp. 20-35.

11. K o 1 m, P. N., R. T u t u n c u, F. J. F a b o z z i. 60 Years of Portfolio Optimization: Practical Challenges and Current Trends. - European Journal of Operational Research, Vol. 234, 2014, pp. 356-371. https://doi.org/10.1016/j.ejor.2013.10.060

12. S t o i 1 o v, T., K. S t o i 1 o v a, M. V l a d i m i r o v. Analytical Overview and Applications of Modified Black-Litterman Model for Portfolio Optimization. - Cybernetics and Information Technologies, Vol 20, 2020, No 2, pp. 30-49.

13. K h a n, K. I., S. M. W. A. N a q v i, M. M. G h a f o o r, R. S. I. A k a s h. Sustainable Portfolio Optimization with Higher-Order Moments of Risk. - J. Sustainability, Vol. 12, 2020, No 5. https://doi.org/10.3390/su12052006

14. B o d i e, Z., A. K a n e, A. M a r c u s. Investments. Sofia, Naturela, 2000. 906 p.

15. https://www.nsi.bg/sites/default/files/files/data/timeseries/HPI_1.3.xls

16. https://www.nsi.bg/sites/default/files/files/data/timeseries/HPI_2.6.xls

17. S u k o n o, P. S., A. T a 1 i b B i n B o n, S. S u p i a n. Modeling of Mean-VaR Portfolio Optimization by Risk Tolerance When the Utility Function is Quadratic. - In: Proc. of AIP Conference, 1827 (020035), 2017. https://doi.org/10.1063/1.4979451

18. S c h u $1 \mathrm{~m}$ e r i c h, M., Y. M. L e p o r c h e r, C. H. E u. Applied Asset and Risk Management. A Guide to Modern Portfolio Management and Behavior-Driven Markets, Vol. XVII, 2015, 476 p. ISBN 978-3-642- 55443-8.

19. K o h $1 \mathrm{~m}$ a n n, M., S. T a n g. Minimization of Risk and Linear Quadratic Optimal Control Theory. SIAM. - J. Control Optim., Vol. 42, 2003, No 3, pp. 1118-1142. https://doi.org/10.1137/S0363012900372465

20. S h a r p e, W. Adaptive Asset Allocation Policies. - J. Financial Analysts, Vol. 66, 2010, No 5, pp. 45-49. https://doi.org/10.2469/faj.v66.n3.3

21. M a 1 z, A. M. Financial Risk Management: Models, History, and Institution. John Wiley \& Sons, Inc., 2011. $722 \mathrm{p}$.

22. S t o i l o v, T., K. S t o i l o v a, M. V l a d i m i r o v. Decision Support for Portfolio Management by Information System with Black-Litterman Model. - International Journal of Information Technology and Decision Making, Vol. 20, 2021, pp. 1-22. DOI: $10.1142 / \mathrm{S} 0219622021500589$, ISSN: 0219-6220.

23. M a r k o w i t z, H. Portfolio Selection. - Journal of Finance, Vol. 7, 1952, pp. 77-91. https://www.math.hkust.edu.hk/ maykwok/courses/ma362/07F/markowitz_JF.pdf 
24. L i u, C., H. S h i, L. W u, M. G u o. The Short-Term and Long-Term Trade-Off between Risk and Return: Chaos vs Rationality . - Journal of Business Economics and Management, Vol. 21, 2020, No 1, pp. 23-43.

https://doi.org/10.3846/jbem.2019.11349

25. T a, V. D., C. M. L i u, D. A. T a d e s s e. Portfolio Optimization-Based Stock Prediction Using Long-Short Term Memory Network in Quantitative Trading. - J. Appl. Sci., Vol. 10, 2020, 437. https://doi.org/10.3390/app10020437

26. X i a o, J., X. Z h u, C. H u a n g, X. Y a n g, F. W e n, M. Z h o n g. A New Approach for Stock Price Analysis and Prediction Based on SSA and SVM. - International Journal of Information Technology \& Decision Making, Vol. 18, 2019, No 1, pp. 287-310. https://doi.org/10.1142/S021962201841002X

27. $\mathrm{H}$ u a $\mathrm{n}$ g, X., X. W a $\mathrm{n}$ g. Portfolio Investment with Options Based on Uncertainty Theory. International Journal of Information Technology \& Decision Making, Vol. 18, 2019. https://doi.org/10.1142/S0219622019500159

28. G a r c í a-G a 1 i c i a, M., A. A. C a r s t e a n u, J. B. C 1 e m p n e r. Continuous-Time Mean Variance Portfolio with Transaction Costs: A Proximal Approach Involving Time Penalization. - International Journal of General Systems, Vol. 48, 2019, No 2, pp. 91-111. https://doi.org/10.1080/03081079.2018.1522306

29. A 11 a j, E. The Black-Litterman Model and Views from a Reverse Optimization Procedure: An Out-Of-Sample Performance Evaluation. - SSRN Electronic Journal, 2019. https://doi.org/10.1007/s10287-020-00373-6

30. B e r t s i m a s, D., V. G u p t a, I. C. P a s c h a 1 i d i s. Inverse Optimization: A New Perspective on the Black-Litterman Model. - J. Oper. Res., Vol. 60, 11 December 2012, No 6, pp.1389-1403. https://doi.org/10.1287/opre.1120.1115

31. B 1 a c k, F., R. L i t t e $\mathrm{r}$ m a n. Asset Allocation: Combining Investor Views with Market Equilibrium. - The Journal of Fixed Income, Vol. 1, 1991, No 2, pp. 7-18. DOI:10.3905/jfi.1991.408013

32. $\mathrm{C}$ h e n, J. M. On Exactitude in Financial Regulation: Value-at-Risk, Expected Shortfall, and Expectiles. - J. Risks, Vol. 6, 2018, No 2, 61. https://doi.org/10.3390/risks6020061

33. W a n g, D., Y. C h e n, H. W a n g, M. H u a n g. Formulation of the Non-Parametric Value at Risk Portfolio Selection Problem Considering Symmetry. - J. Symmetry, Vol. 12, 2020, No 10, 1639. https://doi.org/10.3390/sym12101639

34. S t o i 10 v, T., K. S t o i 1 o v a, M. V 1 a d i m i r o v. The Probabilistic Risk Measure VaR as Constraint in Portfolio Optimization Problem. - Cybernetics and Information Technologies, Vol. 21, 2021, No 1, pp. 19-31.

35. K o b a y a s h i, K., Y. T a k a n o, K. N a k a t a. Bilevel Cutting-Plane Algorithm for Solving Cardinality-Constrained Mean-CVaR Portfolio Optimization Problems. - Computer Science, Mathematics: Optimization and Control. 2020. https://arxiv.org/pdf/2005.12797.pdf

36. B e n i t a, F., F. L ó p e z-R a m o s, S. N a s i n i. A Bi-Level Programming Approach for Global Investment Strategies with Financial Intermediation. - European Journal of Operational Research, Vol. 274, 2019, No 1, pp. 375-390. https://doi.org/10.1016/j.ejor.2018.10.009

37. G a n d o m i, A., M. H a i d e. Beyond the Hype: Big Data Concepts, Methods, and Analytics. International Journal of Information Management, Vol. 35, 2015, pp. 137-144. https://doi.org/10.1016/j.ijinfomgt.2014.10.007 